\title{
Comparison of single and double entry twin cup dosimeter in measuring indoor radon and thoron concentration in Mizoram, India
}

\author{
L.Z. Chhangte ${ }^{1,2}$, P.C. Rohmingliana ${ }^{2}$, B.K. Sahoo ${ }^{3}$, B.K. Sapra ${ }^{3}, V^{2}$ anramlawma ${ }^{1}$, \\ Hmingchungnunga ${ }^{1}$, Remlalsiama ${ }^{1}$, Z. Pachuau ${ }^{1}$, B. Zoliana $^{2^{*}}$

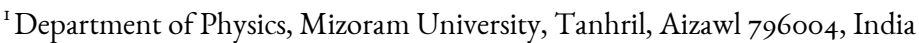 \\ ${ }^{2}$ Department of Electronics, Government Zirtiri Residential Science College, Aizawl 7960oI, India \\ ${ }^{3}$ Radiological Physics and Advisory Division, Bhabha Atomic Research Centre, Mumbai 400085, India
}

\begin{abstract}
Indoor radon and thoron concentrations have been measured using solid state nuclear track detector (LR-115 type-II) based twin cup dosimeter with single and double entry deployed side by side. The measurements have been carried out in 50 dwellings of 8 different villages/ towns situated in Saiha and Lawngtlai districts, Mizoram. Dwellings were selected primarily from the gamma level measured using Micro-R survey meter and the construction type of the building. The average concentrations of radon and thoron were found to be $75.76 \mathrm{~Bq} / \mathrm{m}^{3}$ and $96.50 \mathrm{~Bq} / \mathrm{m}^{3}$ for single entry dosimeter and $63.47 \mathrm{~Bq} / \mathrm{m}^{3}$ and $19.79 \mathrm{~Bq} / \mathrm{m}^{3}$ for double entry dosimeter. The single entry dosimeter was found to give more reliable observations than that of double entry in terms of trends of seasonal data and also on the theory behind the manufacturing qualities.
\end{abstract}

Keywords: Twin cup dosimeters, radon, thoron, solid state nuclear track detectors, gamma level. Received 15 December 2017
Accepted 26 February 2018

*For correspondence $\square$ : bzoliana@gmail.com

\section{Introduction}

Radon $\left.{ }^{222} \mathrm{Rn}\right)$ is a natural radioactive gas, which is produced from radium $\left({ }^{224} \mathrm{Ra}\right)$ and which in turn is a decay product of uranium $\left({ }^{238} \mathrm{U}\right)$, is continually formed in soil and released to the air through the processes called emanation and exhalation. ${ }^{1-5}$ It is now widely understood that the most important component of radiation exposure to the public is due to the inhalation of indoor radon, thoron and their decay products. Even more significant is that the estimated level of health risk associated with average indoor radon levels is much higher than those due to other environmental carcinogens. Monitoring in various countries ${ }^{6}$ yields average residential ${ }^{222} \mathrm{Rn}$ concentrations ranging from 10 to $100 \mathrm{~Bq} / \mathrm{m}^{3}$. The indoor concentration and its decay products depends on three factors; the entry or production rate from various sources, the ventilation rate and the rates of chemical or physical transformation or removal.

The main sources of indoor radon, thoron and their decay products are the soil-gas, minerals and rocks in the earth's crust, building material and ground water. Type of houses, ground 
soil, ventilation rate, atmospheric pressure and temperature affects the equilibrium factor, which also has a significant role in indoor gas measurements. Radon's daughter elements can be hazardous than radon itself unless it is concentrated in an enclosed space. ${ }^{8}$ As radon gas is inhaled, densely ionizing alpha particles emitted by the short-lived (3.82 days) decay products of radon (212Po and ${ }^{214} \mathrm{Po}$ ) can interact with biological tissue in the lungs leading to DNA damage and results into lung cancer. ${ }^{9}$ The world average of annual effective dose to the human by natural radiation is $2.4 \mathrm{mSv} / \mathrm{y}$ and about half of which is due to internal exposure to progenies of radon and thoron. ${ }^{10}$ Thus, it is of fundamental importance to measure their concentration correctly.

In the present study, passive measurement technique of radon and thoron has been followed, using solid state nuclear track detector (SSNTD) LR-115, type-II based twin cup dosimeter with single ${ }^{11}$ and double entry. ${ }^{12-13}$ These dosimeters were developed in Bhabha Atomic Research Centre (BARC), Mumbai.

\section{Materials and Methods}

\section{Dosimeters}

The twin cup dosimeter with double entry consists of a cylindrical plastic chamber divided into two equal compartments, each having a length of $4.1 \mathrm{~cm}$ and height $3.1 \mathrm{~cm}$. The LR-115 type II films are then inserted at the compartments. The SSNTD placed in one compartment measures radon alone which diffuses into it from the ambient air through a semi-permeable membrane of $25 \mu \mathrm{m}$ thickness. It allows the build-up of about $90 \%$ of the radon gas in the compartment and suppresses thoron gas concentration by more than $99 \%$. On the other hand, the glass fiber filter paper of thickness $0.56 \mathrm{~mm}$ in the other compartment allows both radon and thoron gases to diffuse in and hence the tracks on SSNTD placed in this chamber are related to the concentrations of both the gases. However, the estimation of the gas concentrations using this dosimeter was based on the assumption of the same entry rate of the gases into the two cups of the dosimeter, which may not be valid for dosimeters deployed in turbulent environmental conditions. To overcome this limitation, a new pin-hole based ${ }^{222} \mathrm{Rn} /{ }^{220} \mathrm{Rn}$ discriminating measurement device has been developed (Fig. 1).

The new design of this dosimeter system has two compartments separated by a central pinholes disc made up of High Density Polyethylene (HDPE) material, acting as ${ }^{220} \mathrm{Rn}$ discriminator. Each chamber has a length of $4.1 \mathrm{~cm}$ and radius of $3.1 \mathrm{~cm}$ (same dimensions as in the twin cup dosimeter. ${ }^{14}$ The first compartment (named as 'radon + thoron' chamber) samples ambient air
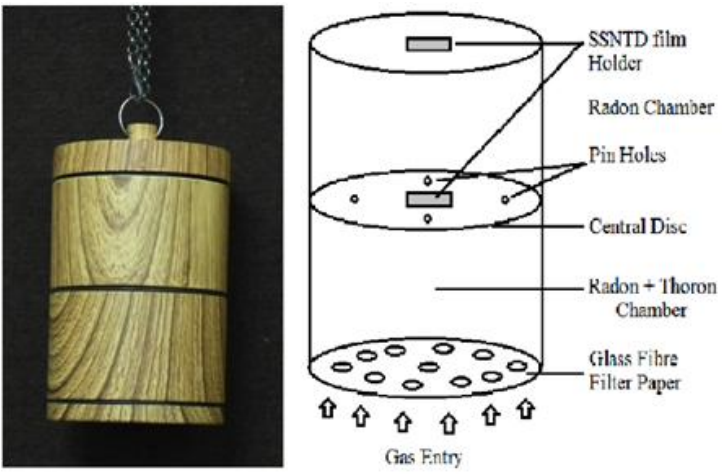

Figure 2 | Single entry dosimeter.

Figure 1 | Double entry dosimeter. 
at the entry of which, the particulates are restricted by using a filter paper. The air containing radon and thoron from this compartment diffuses to the second compartment (named as "radon" chamber) through four pin-holes of 0.5 $\mathrm{mm}$ radius, acting as a diffusion barrier that cuts off the entry of thoron into this chamber due to its short half-life (55.6 s). Hence, only radon enters into this compartment. The tracks registered in LR-115 placed in first and second chamber are corresponding to the radon + thoron and radon concentration in the atmosphere respectively.

Salient features of the device include (i) the pinholes act as ${ }^{222} \mathrm{Rn} /{ }^{20} \mathrm{Rn}$ discriminator and eliminate the requirement of membrane filter used in the earlier twin cup design (ii) the single entrance design for gas transmission and (iii) use of multiple pinholes of reasonably small radius minimises effect of turbulence on ${ }^{222} \mathrm{Rn} /{ }^{220} \mathrm{Rn}$ transmission factors so that the calibration factor is independent of indoor turbulence.

\section{Measurements}

The two types of dosimeter with LR-115 typeII plastic track detectors (SSNTDs) kept inside them was deployed side by side in 50 dwellings of 8 different villages of Lawngtlai and Saiha districts, Mizoram India from 10 January 2017 to 10 May 2017. Due to maximum occupancy, bed rooms were chosen for deployment of the dosimeters. The GPS co-ordinates have also been recorded for each dwelling in which dosimeters were installed for proper location assessments. The dwellings in each village were selected on the basis of gamma readings as well as construction type of the buildings. ${ }^{15}$

After four months of exposure in dwellings, the detectors were removed and subjected to chemical etching in $2.5 \mathrm{~N} \mathrm{NaOH}$ solutions at $60^{\circ} \mathrm{C}$ for 90 minutes in a constant temperature bath. Then these films were washed and dried. The track density was obtained by using the standard spark counter (Model PSI-SC1) with operating voltage $(500 \mathrm{~V})$ and the pre-sparking voltage $(900 \mathrm{~V})$ of the spark counter, which has been es- tablished before these measurements. ${ }^{16}$

\section{Calculation}

Formula used for calculating radon concentration from the track density of radon chamber of the dosimeter.

$$
C_{R}\left(B q / m^{3}\right)=\frac{T_{R}}{C F \times T}
$$

where $C_{R}$ is the radon concentration and $T_{R}$ is the tract density of films in radon chamber. $T$ is the exposure period in days. Calibration factor ${ }^{11}$ (CF) used are $0.0172 \pm 0.002$ for single entry dosimeter and $0.021 \pm 0.0004$ for dual entry dosimeter ${ }^{14}$.

Formula used for calculating thoron concentration from the track density of radon + thoron chamber of the dosimeter.

$$
C_{T}\left(B q / m^{3}\right)=\frac{T_{F}-T_{P}}{C F \times T}
$$

where $C_{T}$ is the thoron concentration, $T_{F}$ is the track density of films in radon chamber and $T_{P}$ is that for radon + thoron chamber. $\mathrm{T}$ is the exposure period in days. Calibration factor ${ }^{11}$ (CF) used are $0.010 \pm 0.001$ for single entry dosimeter and $0.019 \pm 0.002$ for dual entry dosimeter. ${ }^{14}$

\section{Result and Discussion}

Figure 3 show the comparison graph for the concentration of indoor radon measured with single and double entry twin cup dosimeters. The radon concentration measured with the single-entry dosimeter range from 27.09-206.29 Bq/ $\mathrm{m}^{3}$ with the average value of $75.76 \mathrm{~Bq} / \mathrm{m}^{3}, \mathrm{GM}$ of $69.58 \mathrm{~Bq} / \mathrm{m}^{3}, \mathrm{SD}$ of 34.67 and GSD of 1.49 , whereas double entry dosimeter registers the concentration range of $32.42-109.06 \mathrm{~Bq} / \mathrm{m}^{3}$ with the average value $63.47 \mathrm{~Bq} / \mathrm{m}^{3}, \mathrm{GM}$ of $61.52 \mathrm{~Bq} /$ $\mathrm{m}^{3}$, SD of 16.21 and GSD of 1.28 . The single-entry dosimeter registers higher concentration value in $60 \%$ of the dwellings where the two types of dosimeter are deployed.

Figure 4 shows the comparison graph for the concentration of indoor thoron measured with single and double entry twin cup dosimeters. The thoron concentration measured with the 


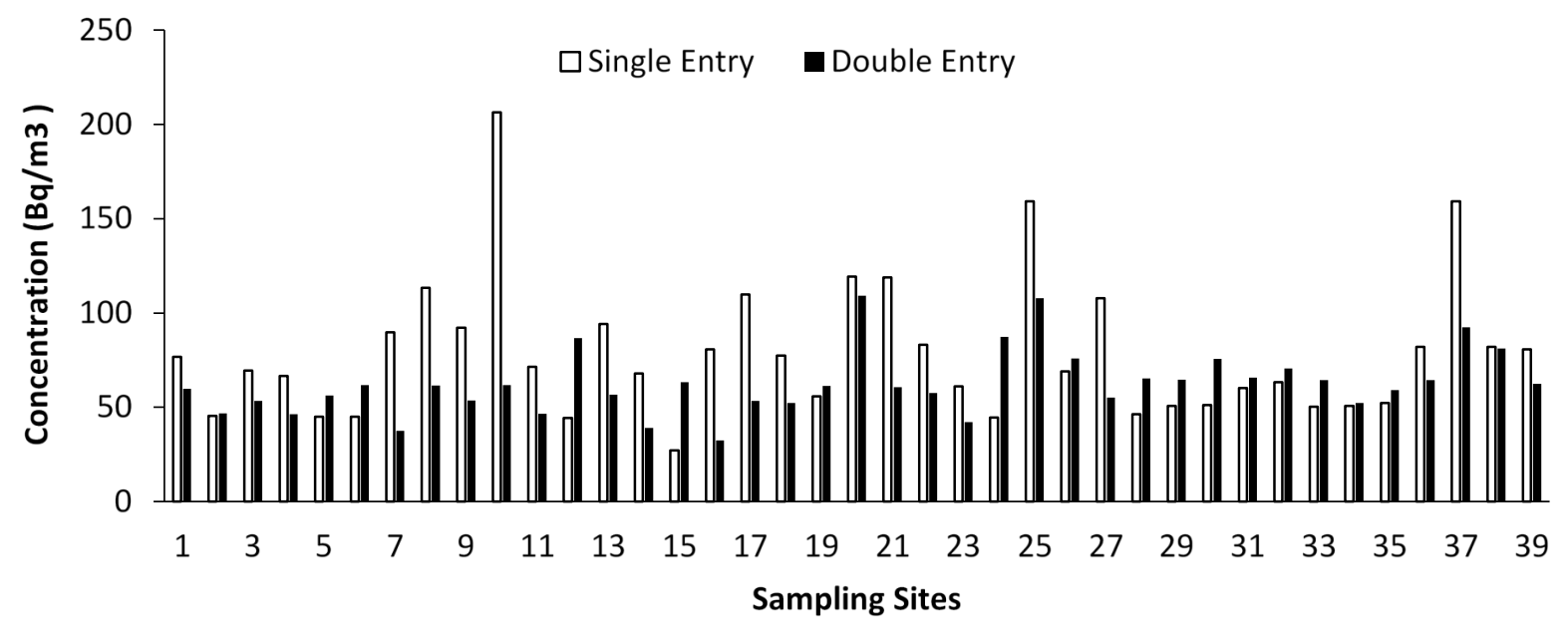

Figure 3 | Radon concentration from single and double entry dosimeter.

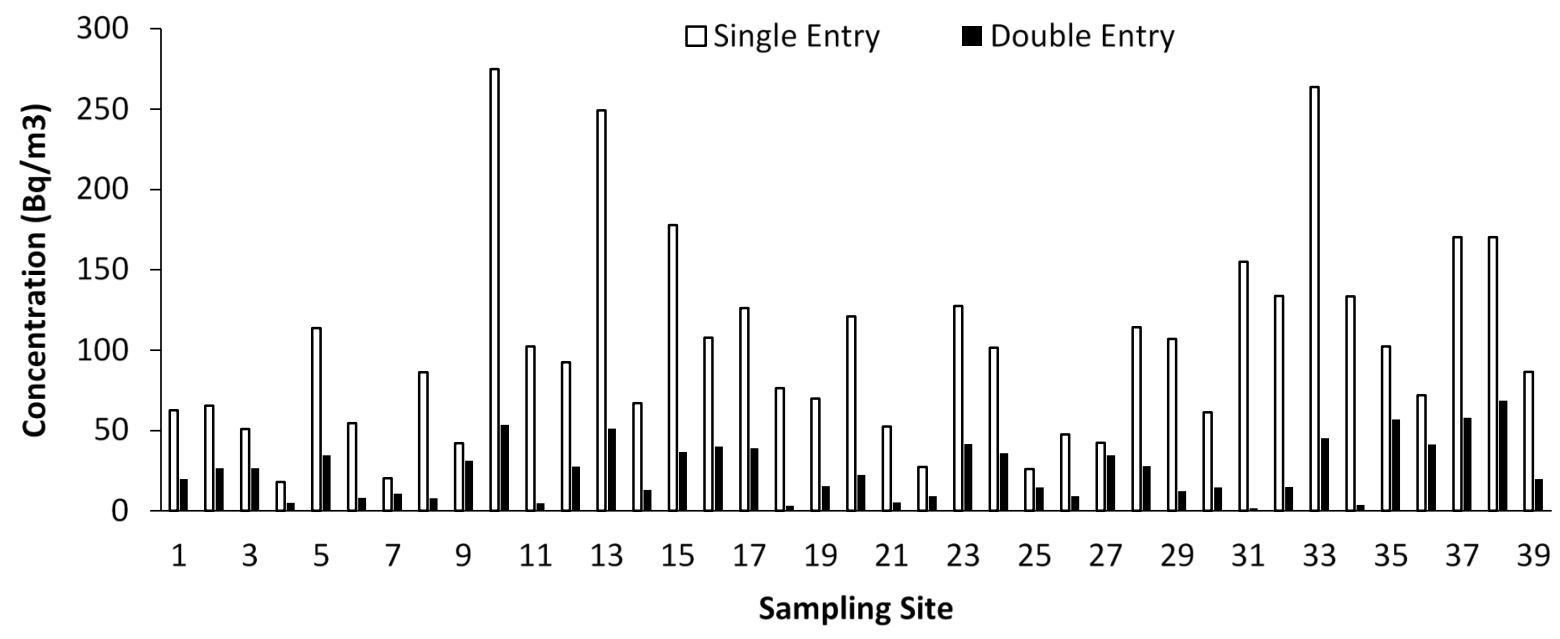

Figure 4 | Thoron concentration from single and double entry dosimeter.

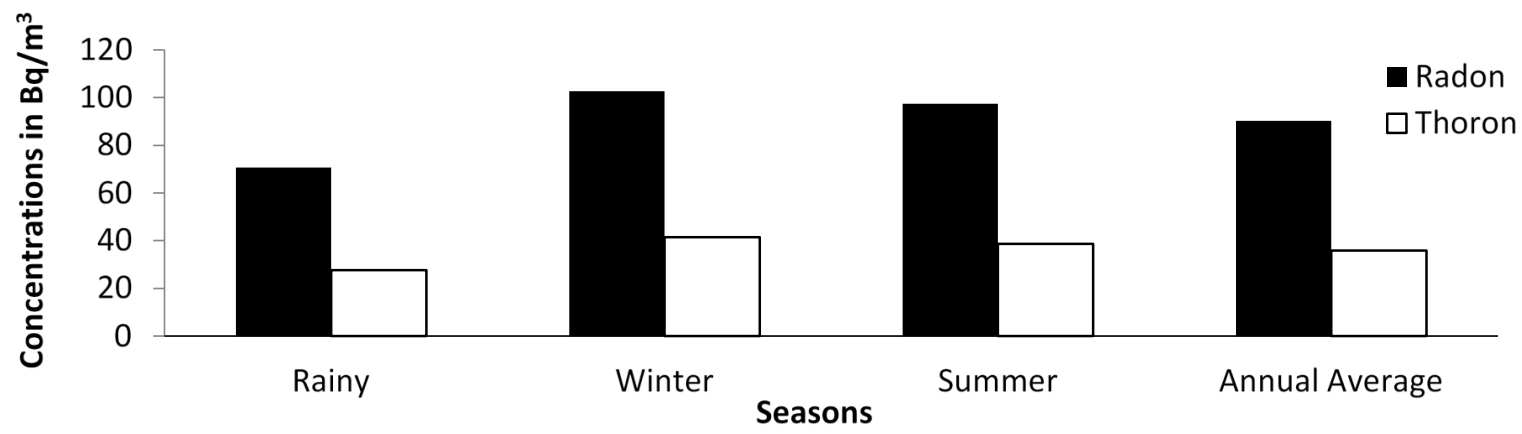

Figure 5 | Seasonal variations of radon/thoron using single entry twin cup dosimeter. 
single-entry dosimeter range from 17.98-177.97 $\mathrm{Bq} / \mathrm{m}^{3}$ with the average value of $89.34 \mathrm{~Bq} / \mathrm{m}^{3}, \mathrm{GM}$ of $76.93 \mathrm{~Bq} / \mathrm{m}^{3}$, SD of 44.31 and GSD of 1.81 whereas double entry dosimeter registers the concentration range of $1.78-68.69 \mathrm{~Bq} / \mathrm{m}^{3}$ with the average value $23.48 \mathrm{~Bq} / \mathrm{m}^{3}, \mathrm{GM}$ of $16.88 \mathrm{~Bq} / \mathrm{m}^{3}$, SD of 17.18 and GSD of 1.68. The single-entry dosimeter registers higher concentration value in all of the dwellings where the two types of dosimeter are deployed. The high value of radon and thoron concentration registered are all in full concrete type of building with one of the walls adjacent to the soil.

Our result shows that indoor concentration of radon and thoron register by the single-entry dosimeter is comparatively higher than those of the double entry dosimeter. At the same time, the size and dimension of pin-hole in single cup dosimeter were exactly as specified. However, the manufacturer's defect was seen in some of the double entry twin cup dosimeters where the size of pin hole was not regular, but tapering at the end. The error made with the assumption of equal entry of the gas in both sides of the double entry dosimeter and the ventilation system of dwellings may not play much role in this the gas concentration while the dosimeters are deployed.

Besides, it is also found that single entry dosimeters data ${ }^{17}$ obeys the trend that is expected for seasonal concentration of the gases (Fig. 5) viz. it is highest in winter followed by summer and lowest in rainy season where we do not have such observation in previous data. ${ }^{18}$

Thus, we have concluded that for passive long time integrated method of measurement, the use of single-entry cup dosimeter may be more reliable than that of double entry dosimeter.

\section{Acknowledgement}

The authors are grateful to Radiological Physics and Advisory Division, Bhabha Atomic Research Center for providing necessary equipment and all the resident in the study area who have helped in carrying out this study.

\section{References}

I. Menon, M.R., Lalith,B .Y. \&Shukla, V.K. (1987). Natural radioactivity in building materials in India. Bullettin of Radiation Protection I4, 45-48.

2. Shukla, V.K., Ramachandran, T.V., Chinnasakki, S., Sartendal, S.J. \& Shanbhag, A.A. (2005). Radiological impact of utilization of phophogypsum and fly ash in building materials in India. International Science Congress Series 1276, 339-340.

3. Sahoo, B.K., Nathwani, D., Eappen, K, P., Ramachandran, T.V., Gaware, J.J. \& Mayya, Y.S. (2007). Estimation of radon emanation factor in indian building materials. Radiation Measurements 42, I422I425.

4. Sahoo, B.K. (2008). Theory of radon emanation and method of source term estimation by flux measurement technique. Proceedings of DAE - BRNS Theme Meeting, Radon - 2008, I8-24, March II-I3, 2008.

5. Sahoo, B.K. \& Mayya, Y.S. (2010). Two-dimensional diffusion theory of trace gas emission into soil chambers for flux measurements. Agriculture and Forest Meteorology I50, I2II-I224.

6. Nazaroff, W.W. \& Nero, A.V. (1988). Radon and its Decay Products in Indoor Air. John Wiley \& Sons, New York.

7. Abu-Jarad, F. \& Fremlin, J.H. (1983). Effect of internal wall covers on radon emanation inside houses. Health Physics Journal 44(3), 243-248.

8. Majumdar, D. (2000). Radon in the environment and associated health problems. Resonance July, 44-55.

9. Edling, C., Wingreen, G., \& Axelson, O. (1986). Quantification of the lung cancer risk from radon daughter exposure in dwellings - An epidemiological approach. Environment International $\mathbf{1 2}(\mathrm{I}-4), 55-60$.

Io. UNSCEAR. United Nations Scientific Committee on the effects of Atomic Radiation. Sources, effects and risks of ionizing radiation, United Nations 2000.

II. Sahoo, B.K., Sapra, B.K., Kanse, S.D, Gaware, J.J \& Mayya Y.S. (2013). A new pin-hole discriminated ${ }^{222} \mathrm{Rn} /{ }^{220} \mathrm{Rn}$ passive measurement device with single entry face. Radiation Measurements 58, 52-60.

I2. Mayya, Y.S., Eappen, K.P. \& Nambi, K. S.V. (1998). Methodology for mixed field inhalation dosimetry in monazite areas using a twin cup dosimeter with three track detectors. Radiation Protection Dosimetry 77, I77I84.

13. Nambi, K.S.V., Ramu, M.C.S., Eappen, K.P., 
Ramachandran, T.V., Muraleesharan, T.S. \& Shaikh, A.N. (1994). A new SSNTD method of combined measurement of radon and thoron working levels in atmosphere. Bulletin of Radiation Protection $\mathbf{1 7}, 34-35$.

I4. Eappen, K.P. \& Mayya, Y.S. (2004). Calibration factors for LR-IIs (Type-II) based radon thoron discriminating dosimeter. Radiation Measurements 38, 5-17.

I5. Vanchhawng, L. (2012). Measurement of radon, thoron and their progeny concentrations in Mizoram with special reference to Aizawl, Champhai and Kolasib Districts. Unpublished $\mathrm{PhD}$ thesis at Mizoram University.

16. Azimi-Garakani, D., Shahbazi, M. \& Latifi, G. (198I). A new automatic spark counting system. Nuclear Tracks 4, I4I-I48.
17. Chhangte, L.Z., Rohmingliana, P.C., Sahoo, B.K., Sapra, B.K., Zoliana, B. \& Pachuau, Z. (20I7). Seasonal variation of indoor radon and thoron concentration in Mizoram, India. Presented at $20^{\text {th }}$ National Conference on Solid State Nuclear Track Detectors and their Application at Vidya Vikas Institute of Engineering and Technology, Mysuru on 26-28, October, 2017.

I8. Rohmingliana, P.C., Lalmuanpuia. V., Thapa, R.K., Sahoo, B.K., Mishra, R, Mayya, Y.S. \& Zoliana, B. (20II). Seasonal variation of radon/thoron and their progeny concentration in Saiha District, Mizoram, India. Advances in Environmental Chemistry 15, 193-195. 